\title{
The Dynamics of Contact Interaction during the Cutting Process
}

\author{
Dmitriy V. Vasilkov \\ Baltic State Technical University «VOENMEH» \\ St. Petersburg, 190005, Russia \\ Corresponding author: vasilkov_dv@voenmeh.ru \\ Alexander V. Nikitin \\ Peter the Great St. Petersburg Polytechnic University \\ St. Petersburg, 195220, Russia \\ E-mail: nikitin_av@spbstu.ru \\ Igor Y. Tarikov \\ Baltic State Technical University «VOENMEH» \\ St. Petersburg, 190005, Russia \\ E-mail: yaiv@mail.ru
}

(Received December 23, 2018; Accepted June 7, 2019)

\begin{abstract}
At parts manufacturing using metal-cutting machine tools, the process conditions eliminating high vibration levels are among the most important factors ensuring safe operation of the said metal-cutting machine tools. To solve the task, specific features typical for creation of the dynamic model of mechanical processing in the space of condition variables at contact interaction in the cutting zone based on the piecewise linear approximation were discussed. The contact interaction process was considered as the double-phase one envisaging sequence of retention at adhesion and sliding at adhesion bonds rupture. The cutting tool' and the workpiece' contact interactions are presented in the form of rheological models. Conditions of retention and sliding phases sequence are formed by the system itself that is the self-excited one. The set of research performed allowed considering contact interaction of the machined surface with the rear surface of the tool and the of the moving chip with the anterior surface of the tool with the anterior surface of the tool as factors largely defining the conditions of self-sustained oscillations. The contact interaction' double-phase nature ensures selforganised dosing and selectiveness of the dynamic contours at interaction in the autonomous dynamic process system.
\end{abstract}

Keywords- Process system, Cutting process dynamic model, Rheological equations, Sliding, retention, Piecewise linear approximation.

\section{Introduction}

At parts manufacturing using metal-cutting machine tools, the process conditions eliminating high vibration levels are among the most important factors ensuring safe operation of the said metalcutting machine tools. Vibrations lead to loss of precision, premature failure of the equipment and cutting tool wear. To solve the problem, the set of studies aimed at investigating dynamics of the mechanical treatment' process system (Kudinov, 1967; Elyasberg, 1993; Vasilkov et al., 2004; Maksarov, 2015; Olt et al., 2016; Temraz. 2018; Skeeba and Ivancivsky, 2018; Maksarov and Efimov, 2018). Analysis of processes taking place at contact interaction of chippings with the anterior surface of the tool and of the machined surface with the rear surface of the tool allowed presenting the process as the double-phase one: with the retention and sliding phases (Vasilkov et al., 1997; Maksarov et al., 2017, Vasilkov, 2018). As compared to the conventional approach to the equilibrium conditions at the cutting wedge and the treated material interaction a new approach has been introduced. Specifically, molecular processes occurring in the chip formation zone are 
International Journal of Mathematical, Engineering and Management Sciences

Vol. 4, No. 5, 1218-1227, 2019

https://dx.doi.org/10.33889/IJMEMS.2019.4.5-096

presented in the form of rheological models connecting subsystems of the workpiece and the cutting tool (Olt and Maksarov, 2015; Olt et al., 2016b). In the model, the discussed processes are presented as viscoelastic model of Voigt, Maxwell's visco-hereditary model, or as more complex media modified relative to the discussed task. Conditions of interaction of elastic-dissipative and inertial characteristics of the technological system and viscoelastic-plastic characteristics in the chipformation zone are modelled.

Conditions ensuring sequence of the retention and sliding phases at interaction of the anterior surface of the tool and the rear surface of the tool with, respectively, the moving chip and the machined surface are formed by the system itself that potentially is self-excited one (Zhukov et al., 2016; Skvortsova and Nurulin, 2018; Völkers et al., 2018).

The principal idea underlying the discussed approach is piecewise linear approximation of the contact interaction in the technological system (TS) directly within the cutting process. The said idea consists of considering the contact interaction at cutting as sequence of states either of which can be presented by its rheological models complex. At that, sequence functions are formed that determine conditions for transfer from one state to another (Vasilkov et al. 2018).

Differential equations system describing dynamic processes taking place in the TS in the space of condition variables is expressed as follows:

$\dot{u}=D u+S(u)$

where $\mathrm{u}$ is condition variables vector; $\mathrm{D}$ is transfer matrix with the constant coefficients; $\mathrm{S}$ is vectorfunction of the piecewise linear type.

It should be noted that at contact interaction, the processes taking place on the anterior and rear surfaces of the tool are connected. Let us discuss a double-loop TS as an example (Figure 1). It includes two joint coordinates y, z. Chip-formation zone 1 is considered as the connected dynamic subsystem that, in turn, has two double-loop subsystems: on the side of the the anterior and rear surfaces of the tool (Khoromskij and Repin, 2015; Abushawashi et al., 2017).

Elastic-dissipative characteristics of the TS are defined by the following parameters: $c y, c z$, by, $b z$ coefficients of stiffness (factor of rigidity) and dissipation in the direction of $y, z$ axes (Garshin et al., 2017; Mirsaidov et al., 2018).

Description of metal movement in the chip-formation zone using rheological models makes it possible to substitute differential equations in partial derivative with the ordinary differential equations. It clearly simplifies mathematics of modelling dynamic interactions at cutting (Kolodyazhniy et al., 2016; Klochkov et al., 2019). 
International Journal of Mathematical, Engineering and Management Sciences

Vol. 4, No. 5, 1218-1227, 2019

https://dx.doi.org/10.33889/IJMEMS.2019.4.5-096



Figure 1. Double-loop dynamic model of the technological system

\section{Materials and Methods}

In accordance with the rheological presentation from the direction of the rear surface of the tool, viscous-elastic interaction with the machined surface occurs. Rheology of the near-surface zone of the part' material from the direction of the rear surface of the tool (RST) is modelled by RYR and RZR (Figure 2). From the direction of the anterior surface of the tool (AST) viscoelastic-plastic interaction takes place and is modelled by elements RYA and RZA. Variants of subsystem formation from the direction of the tool' anterior surface exist where front angle (positive or negative), slip bands, etc. are considered.

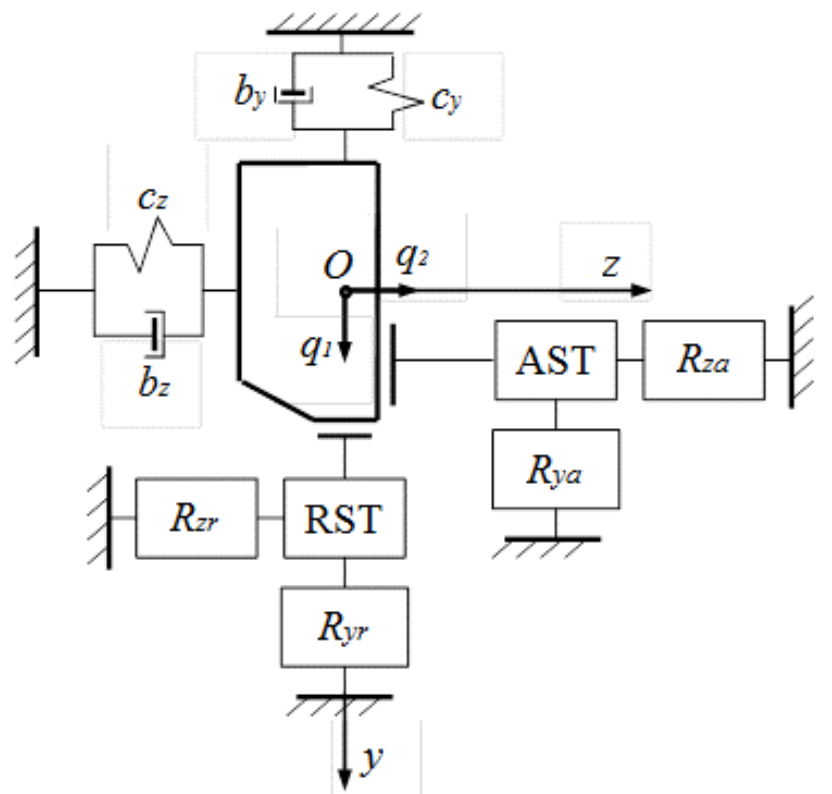

Figure 2. Rheological presentation of force interactions in the cutting zone 
International Journal of Mathematical, Engineering and Management Sciences

Vol. 4, No. 5, 1218-1227, 2019

https://dx.doi.org/10.33889/IJMEMS.2019.4.5-096

Let us pass from the generalized coordinates $q_{1}=y, q_{2}=z$ (Figure 1) to the condition variables state $u_{1}=z ; u_{2}=\dot{z} ; u_{3}=y ; u_{4}=\dot{y} ; u_{5}=R_{z}^{(s h)} ; u_{6}=R_{y}^{(s h)} ; u_{7}=R_{z}^{(m o l)} ; u_{8}=R_{y}^{(m o l)} ; u_{9}=R_{z}^{(m e c h)} ; u_{10}=R_{y}^{(m e c h)}$

where $R_{z}^{(s h)}, R_{y}^{(s h)}, R_{z}^{(m o l)}, R_{y}^{(m o l)}, R_{z}^{(m e c h)}, R_{y}^{(m e c h)}$ - shearing, molecular (at adhesion), mechanical (at sliding) components of cutting force.

Transformation matrix $D$ has the following distinct from zero elements in the expanded rheological model (Figure 3):



Figure 3. Expanded rheological model 
International Journal of Mathematical, Engineering and Management Sciences

Vol. 4, No. 5, 1218-1227, 2019

https://dx.doi.org/10.33889/IJMEMS.2019.4.5-096

$d_{1,2}=d_{3,4}=1 ; d_{2,1}=-\frac{c_{z}}{m} ; d_{2,2}=-\frac{b_{z}}{m} ; d_{2,5}=d_{2,7}=d_{2,9}=d_{4,6}=d_{4,8}=d_{4,10}=\frac{1}{m} ; d_{4,3}=-\frac{c_{y}}{m} ; d_{4,4}=-\frac{b_{y}}{m}$

$; d_{5,5}=-\frac{1}{T_{z}^{(s h)}} ; d_{5,1}=-\frac{c_{z a}}{T_{z}^{(s h)}} ; d_{5,2}=-\frac{b_{z a}}{T_{z}^{(s h)}} ; d_{6,3}=-\frac{c_{y a}}{T_{y}^{(s h)}} ; d_{6,4}=-\frac{b_{y a}}{T_{y}^{(s h)}} ; d_{6,6}=-\frac{1}{T_{y}^{(s h)}} ; d_{7,7}=-\frac{1}{T_{z}^{(m o l)}} ;$

$d_{8,8}=-\frac{1}{T_{y}^{(\text {mol })}} ; d_{9,9}=-\frac{1}{T_{z}^{(m e c h)}} ; d_{10,10}=-\frac{1}{T_{y}^{(\text {mech })}}$, where $\mathrm{m}$ is the reduced mass; $T_{z}^{(s h)}, T_{y}^{(s h)}, T_{z}^{(\text {mol })}$,

$T_{y}^{(m o l)}, T_{z}^{(m e c h)}, T_{y}^{(\text {mech })}$ are constants of molecular-mechanical processes time in dynamic contours; $c_{z a}$ $, c_{z r 1}, c_{z r 2}, c_{y a}, c_{y r 1}, c_{y r 2}, b_{z a}, b_{z r 1}, b_{z r 2}, b_{y a}, b_{y r}$ are elastic-dissipative characteristics in the cutting zone.

Vector-function $S(u)$ has the following distinct from zero components:

$$
\begin{aligned}
& s_{7}=-S g 1\left(\frac{c_{z r}}{T_{z}^{(m o l)}} u_{1}+\frac{b_{z r 1}}{T_{z}^{(m o l)}} u_{2}\right) ; \quad s_{8}=-S g 1\left(\frac{c_{y r 1}}{T_{y}^{(m o l)}} u_{3}+\frac{b_{y r}}{T_{y}^{(m o l)}} u_{4}\right) ; \quad s_{9}=-(1-S g 1) \frac{\mu c_{z r 2}}{T_{z}^{(m o l)}} u_{3} ; \\
& s_{10}=-(1-S g 1) \frac{b_{y r 2}}{T_{y}^{(m o l)}} u_{2} .
\end{aligned}
$$

At contact interaction, transfer from retention to sliding phase and back is modelled by Saint-Venant movable triboelements with $\beta_{z 1}, \beta_{z 2}$ characteristics in tangent contour and $\beta_{y 1}, \beta_{y 2}$ characteristics in normal contour. Sequence function between sliding and retention phases can be expressed as the following relationship:

$$
S g 1=\left\{\begin{array}{l}
1 \text { of } \beta_{z 1}=0, \beta_{y 1}=0, \beta_{z 2}=1, \beta_{y 2}=1,- \text { retention; } \\
0 \text { of } \beta_{z 1}=1, \beta_{y 1}=1, \beta_{z 2}=0, \beta_{y 2}=0 \text { - sliding }
\end{array}\right.
$$

Characteristics of movable triboelements $\beta=1$ (for contours $\mathrm{z}$ and $\mathrm{y}$, respectively) show that the second movable triboelement is absolutely a solid body. It means that only one rheological block takes part in the contact interaction. At that, traceable conditions of sequence are transformed as follows:

$y<-\frac{A_{r}}{c_{y} y_{s}\left[\delta_{k n}\right]}=U, \quad|\dot{z}|<\left|\left[V_{z}\right]\right|$,

where $A_{r}$ is the actual area of contact between the cutter' worn place and the workpiece surface; $y_{s}$ is static deformation of the elastic element with factor of stiffness coefficient $c_{y}$. The fact that vectorfunction $S(u)$ is piecewise linear function is specific feature of the differential equations system (1).

\section{Discussion of the Results}

The discussed dynamic system in the space of condition variables is nonlinear one of the piecewiselinear type. Based on the said dynamic system, it is possible to investigate frequency content and oscillations amplitude level at wide variability of the model' parameters (Dencker et al., 2016; Bulyanitsa et al., 2017).

To assess the movements nature, conditions of the computing experiment shall be formulated. The workpiece specifications: diameter $d=90 \mathrm{~mm}$; material - NiCr20TiAl. The tool specifications: rear 
International Journal of Mathematical, Engineering and Management Sciences

Vol. 4, No. 5, 1218-1227, 2019

https://dx.doi.org/10.33889/IJMEMS.2019.4.5-096

angle $\alpha=80$; anterior angle $\gamma=-80$; main angle in plan $\varphi=700$; auxiliary angle in plan $\varphi_{1}=200$; cutting head material - M101S; toolholder cross-section - 40x20; free length of the console tool holder $-95 \mathrm{~mm}$. Cutting modes: working feed of the tool $-\mathrm{S}=0.19 \mathrm{~mm} / \mathrm{turn}$; cutting depth $-\mathrm{t}=1.0$ $\mathrm{mm}$; cutting speed $-\mathrm{V}=30 \ldots 220 \mathrm{~m} / \mathrm{min}$. Treatment without cooling.

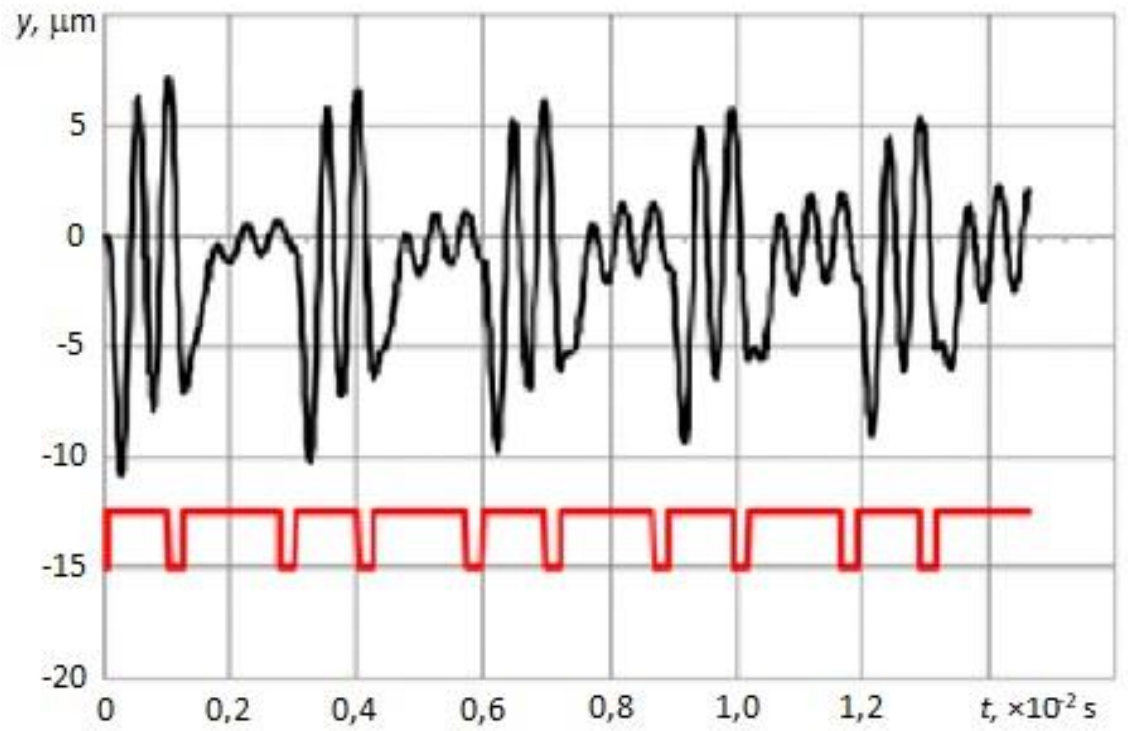

a)

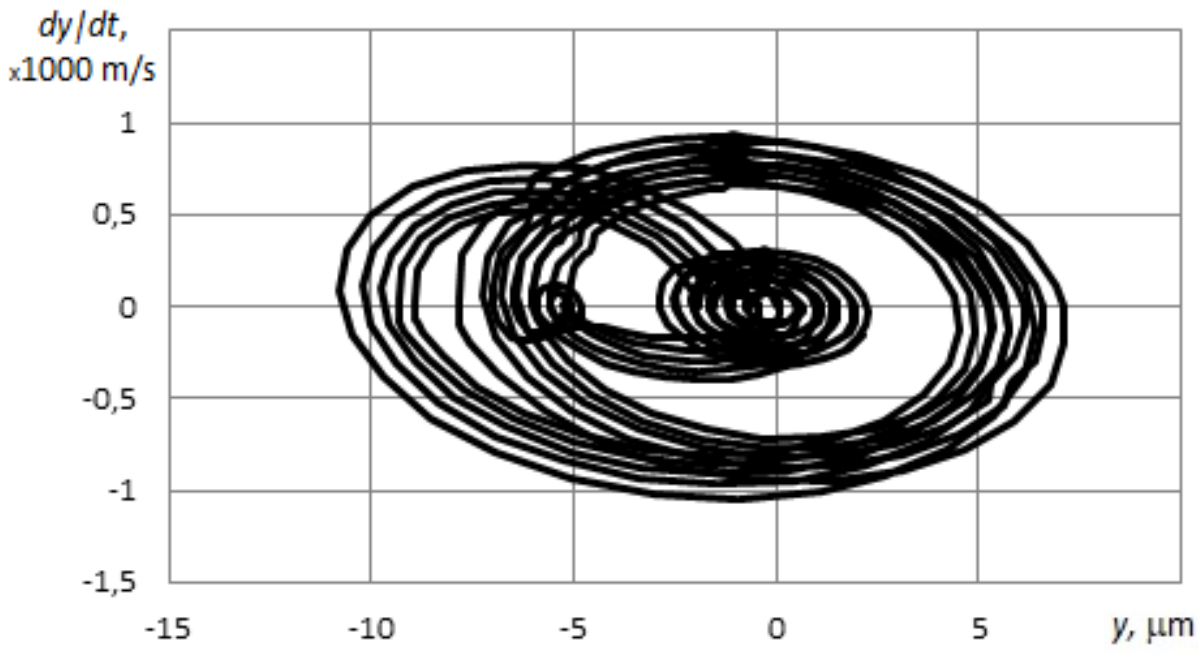

b)

Figure 4. Calculated vibratory displacements at $\mathrm{V}=80 \mathrm{~m} / \mathrm{min}$ (a) and phase-plane portrait (b) 
International Journal of Mathematical, Engineering and Management Sciences

Vol. 4, No. 5, 1218-1227, 2019

https://dx.doi.org/10.33889/IJMEMS.2019.4.5-096



a)

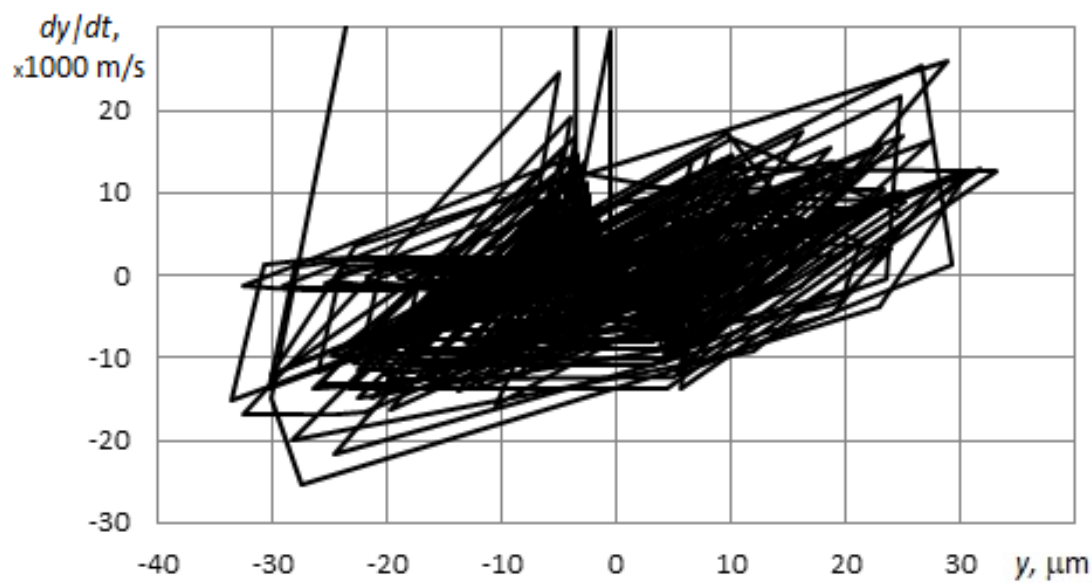

b)

Figure 5. Calculated vibratory displacements at V=60 m/min (a) and phase-plane portrait (b)

Relative vibration displacement along the normal to the forming point of the tool in the direction $y$ (upper curve in Figure 4, a) was produced based on calculation according to the model (1). It gives clear understanding of the periodic solution that is formed as a result of sliding and setting phases sequence. According to the diagrams, transfer from the setting phase to the sliding one is accompanied by the displacement pike y (upper curve in Figure 4, a). At that, phase trajectory escape to the limit cycle with $2-5 \mu \mathrm{m}$ amplitude is observed on the phase-plane portrait (the curve in Figure $4, b)$.

At the moment of the retention phase transition into the sliding phase, typical displacement of the phase trajectory from the limit cycle with 3-12 $\mu \mathrm{m}$ amplitude followed by returning to the limit cycle. The said characteristic behavior of the dynamic system is observed within the cutting speed 
International Journal of Mathematical, Engineering and Management Sciences

Vol. 4, No. 5, 1218-1227, 2019

https://dx.doi.org/10.33889/IJMEMS.2019.4.5-096

range of $\mathrm{V}=30 \ldots 50 \mathrm{~m} / \mathrm{min}$ and within the cutting speed range of $\mathrm{V}=70 \ldots 200 \mathrm{~m} / \mathrm{min}$ (standard diagrams for $\mathrm{V}=80 \mathrm{~m} / \mathrm{min}$ are presented in Figure 4). The retention phase duration for the said modes was, on the average, 10-4c, while the sliding phase was an order of magnitude longer.

At the cutting velocity of $\mathrm{V}=60 \mathrm{~m} / \mathrm{min}$, sharp increase of the vibrations level is observed accompanied by transition to the second limit cycle with $30 \mu \mathrm{m}$ amplitude (Figure 5). The said mode is inadmissible in any case and is excluded from the set of cases possible for implementation.

\section{Conclusions}

The set of studies performed gives grounds for considering contact interaction of the machined surface with the rear surface of the tool and the moving chip with the anterior surface of the tool as factors largely defining conditions for self-induced vibrations generation. Double-phase nature of the contact interaction process self-organises dosing and selectivity of the dynamic contours at interaction in the autonomous dynamic TS. Pulsating nature of movement is manifested in the vibratory displacements' timing diagrams, at turning in particular, which proves the accepted schematization of the dynamic processes at cutting.

Parametrisation of TS' dynamic model is performed based on the traditional model solutions for force interaction at machining transformed into the dynamic characteristics within the range of rheological presentations of adhesive-deformation contact interaction.

\section{Conflict of Interest}

The authors confirm that there is no conflict of interest to declare for this publication

\section{Acknowledgments}

The work is carried out with the financial support of the Ministry of Education and Science of the Russian Federation (agreement No. 14.577.21.0270, unique project number RFMEFI57717X0270).

The research carried out with the financial support of the grant from the Program Competitiveness Enhancement of Peter the Great St.Petersburg Polytechnic University

\section{References}

Abushawashi, Y., Xiao, X., \& Astakhov, V. (2017). Practical applications of the "energy-triaxiality" state relationship in metal cutting. Machining Science and Technology, 21(1), 1-18. doi:10.1080/10910344.2015.1133913.

Bulyanitsa, A.L., Belousov, K.I., \& Evstrapov, A.A. (2017). Applicability of submerged jet model to describe the liquid sample load into measuring chamber of micron and submillimeter sizes. Paper presented at the Journal of Physics: Conference Series, 917(4) doi:10.1088/1742-6596/917/4/042021

Dencker, F., Wurz, M., Dubrovskiy, S., \& Koroleva, E. (2016). An application report: Protective thin film layers for high temperature sensor technology. Paper presented at the Proceedings of the 2016 IEEE North West Russia Section Young Researchers in Electrical and Electronic Engineering Conference, EIConRusNW 2016, 32-36. doi:10.1109/EIConRusNW.2016.7448110.

Elyasberg, M.E. (1993). Self-oscillations of metal-cutting machines: Theory and practice. St. Petersburg: $O K B S .180$ p. 
International Journal of Mathematical, Engineering and Management Sciences

Vol. 4, No. 5, 1218-1227, 2019

https://dx.doi.org/10.33889/IJMEMS.2019.4.5-096

Garshin, A.P., Kulik, V.I., \& Nilov, A.S. (2017). Study of ceramic-matrix composites tribological properties paired with cermet. Procedia Engineering, 206, 771-776. doi:10.1016/j.proeng.2017.10.550.

Khoromskij, B.N., \& Repin, S.I. (2015). A fast iteration method for solving elliptic problems with quasiperiodic coefficients. Russian Journal of Numerical Analysis and Mathematical Modelling, 30(6), 329-344. doi:10.1515/rnam-2015-0030.

Klochkov, Y., Gazizulina, A., \& Muralidharan, K. (2019). Lean six sigma for sustainable business practices: A case study and standardisation. International Journal for Quality Research, 13(1), 47-74. doi:10.24874/IJQR13.01-04.

Kolodyazhniy, D.Y., Lyubomudrov, S.A., \& Makarova, T.A. (2016). Quality assurance issues of hardprocessing aluminum alloy parts fabrication for aircraft construction and engine-building. Journal of Engineering and Applied Sciences, 11(14), 3019-3023. doi:10.3923/jeasci.2016.3019.3023.

Kudinov, V.A. (1967). Dynamics of machines. Moscow: Mechanical Engineering. 359 p.

Maksarov V.V., \& Efimov A.E. (2018). Simulation modeling of dynamic characteristics of machining in NI LabView software environment to improve processing technique of a rod component. IOP Conference Series: Earth and Environmental Science, 194(2), 022021.

Maksarov V.V., Khalimonenko A.D., Matrenichev K.G. (2017). Stability analysis of multipoint tool equipped with metal cutting ceramics. IOP Conference Series: Earth and Environmental Science, 7(8), 082030.

Maksarov, V. (2015). Improving the accuracy of manufacturing of hydraulic power cylinders using vibrationproof cutting tool. Agronomy Research, 13(3), pp. 671-679.

Mirsaidov, M.M., Abdikarimov, R.A., Vatin, N.I., Zhgutov, V.M., Khodzhaev, D.A., \& Normuminov, B.A. (2018). Nonlinear parametric oscillations of viscoelastic plate of variable thickness. Magazine of Civil Engineering, 82(6), 112-126. doi:10.18720/MCE.82.11.

Olt J., \& Maksarov, V.V. (2015). Cutting process simulation on the basis of rheological properties of metals. Annals of DAAAM and Proceedings of the International DAAAM Symposium, 2015-January, pp. 229237.

Olt J., Liivapuu O., Maksarov V., Liyvapuu A., \& Tärgla T. (2016a). Mathematical modelling of cutting process system. In: Silvestrov S., Rančić M. (eds) Engineering Mathematics I. Springer Proceedings in Mathematics \& Statistics, vol 178. Springer, Cham.

Olt, J., Liyvapuu, A., Madissoo, M., \& Maksarov, V. (2016b). Dynamic simulation of chip formation in the process of cutting. International Journal of Materials and Product Technology, 53(1), 1-14.

Skeeba, V.Y., \& Ivancivsky, V.V. (2018, November). Reliability of quality forecast for hybrid metal-working machinery. In IOP Conference Series: Earth and Environmental Science (Vol. 194, No. 2, p. 022037). IOP Publishing.

Skvortsova, I., \& Nurulin, Y. (2018). Accelerator of innovations for pre-incubation stage of project lifecycle. Paper presented at the MATEC Web of Conferences, 170 doi:10.1051/matecconf/201817001004.

Temraz, N.S.Y. (2018). Availability and Reliability Analysis for Dependent System with Load-Sharing and Degradation Facility. International Journal of Systems Science and Applied Mathematics, 3(1), 10-15.

Vasilkov D.V., Chechin V.V., \& Shmakov V.A. (2004). Estimation of technical condition, working capacity and necessity of repair of metal-cutting machines. Tools and Technologies, 16(1), 172-175.

Vasilkov D.V., Nikitin A.V., \& Cherdakova V.S. (2018). Stability of the dynamic system of the machine tool when machining with a blade tool. IOP Conference Series: Earth and Environmental Science, 194, 2 , 022045 . 
International Journal of Mathematical, Engineering and Management Sciences

Vol. 4, No. 5, 1218-1227, 2019

https://dx.doi.org/10.33889/IJMEMS.2019.4.5-096

Vasilkov, D.V., Weitz, B.L., \& Shevchenko, V.S. (1997). Dynamics of the technological system of mechanicalprocessing. Saint-Petersburg: Publishing Tool, 4(1), 194-207.

Völkers, S., Böhm, S., \& Somonov, V. (2018, November). Porosity reduction in the laser beam welding of aluminium die cast alloys through the overlapping of mechanically induced sound waves. In Journal of Physics: Conference Series (Vol. 1109, No. 1, p. 012019). IOP Publishing.

Zhukov, E.L., Kozar, I.I., \& Kolodyazhniy, D.Y. (2016). Problems of ensuring quality of a surface layer when producing components from hard-to-process heat resistant alloys. Acta Metallurgica Slovaca, $22(2), 128-132$. 